Research Article

\title{
Study of expression patterns of cytokeratin 8 and 18 in oral cancers
}

\author{
Mitra S.K ${ }^{1}$, Mishra R.K ${ }^{2}$, Rai R. ${ }^{3}$, Rai $\mathbf{P}^{4}$, Arya M.L ${ }^{5}$ \\ ${ }^{1}$ Dr. Shaila Kumari Mitra, Associate Professor, Department of Pathology, ${ }^{2}$ Dr. R. K. Misra, Professor and Head, \\ Department of Pathology, ${ }^{3}$ Dr. Rajesh Rai, Associate Professor, Department of Pathology, ${ }^{4}$ Dr. Priyanka Rai, Resident, \\ Department of Pathology; above all authors are affiliated with B. R. D. Medical College, Gorakhpur, UP, India, \\ ${ }^{5}$ Dr. Murari Lal Arya, Officer in charge, Blood bank, MLB Medical College, Jhansi, UP, India
}

Address for Correspondence: Dr. Shaila Kumari Mitra, Associate Professor, Department of Pathology, B.R.D.Medical College, Gorakhpur.UP, Email: shaila.prasad14@yahoo.in

\begin{abstract}
Introduction: Squamous cell carcinoma of oral cavity is a morphological heterogenous disease. Cytokeratin (CK) comprises a diverse group of intermediate filament protein that are expressed as pairs in both keratinized and non keratinized epithelial tissue. Very little is known of CK alteration in oral intraepithelial neoplasia III (OIN III) and invasive squamous cell carcinoma (SCC). The aim of the study is to evaluate the expression pattern of CK8/18 in oral carcinoma and to establish any correlation between the expressions of CK8/18 with tumor differentiation. Material and Methods: A total of 104 cases of Paraffin embedded formalin fixed sections from oral squamous cell carcinomas (N=60) including benign and inflammatory lesions (control; $\mathrm{N}=40)$ and oral intraepithethelial lesions $(\mathrm{N}=4)$ were stained with Haematoxylin and eosin stain and and then studied immunohistochemically using CK8 and CK18 immunomarkers.

Result: Out of 60 cases of invasive squamous carcinomas, cytokeratin 8 showed positivity in 34 cases (56.67\%) while expression of cytokeratin 18 was observed in 25 cases $(41.67 \%)$ but its expression were absent in control and oral intraepithelial cases. Expression of CK 8 was seen in majority of poorly differentiated 4/5 (80\%) followed by moderately differentiated $12 / 17(70.59 \%)$, with its expression were significantly higher $(56.67 \%)$ in invasive oral carcinomas compared with controls statistically. Similarly CK18 expression was seen in majority of poorly $4 / 5$ (80\%) followed by moderately differentiated squamous cell carcinomas 7/17 (41.18\%). Conclusion: Aberrant expression of CK8/18 could be correlated with differentiation and recurrence and shows a great promise to be used as prognostic marker for human oral cancer.
\end{abstract}

Key words: Cytokeratin 8, Cytokeratin 18, Oral squamous cell carcinoma

\section{Introduction}

Oral carcinoma represents a major global health problem. It is the sixth most frequently diagnosed malignancy with high incidence of mortality and morbidity [1].

Manuscript received: $25^{\text {th }}$ August 2016

Reviewed: $10^{\text {th }}$ September 2016

Author Corrected: $20^{\text {th }}$ September 2016

Accepted for Publication: $4^{\text {th }}$ October 2016
In India it ranks among the three most common types of cancer and the age standardized incidence rate of oral cancer is 12.6 per 100000 population [2]. The incidence is at a rise because of increase in alcohol and tobacco consumption. There are several types of oral cancers, but around $90 \%$ are squamous cell carcinomas [3], most commonly involve the tongue. Often oral cancer is 
diagnosed when the cancer has metastasized to another location, most likely the lymph node of the neck. Prognosis is poor at this stage and the primary tumor has had time to invade deep into local structures [3]. Cytokeratins (CK) comprise a diverse group of intermediate filament protein that are expressed as pairs in both keratinized and non keratinized epithelial tissue. CK play a critical role in differentiation and tissue specialization and function to maintain the overall structural integrity of epithelial cells and have been found to be useful markers of tissue differentiation which is directly applicable to characterization of malignant tumors [4].

The expression of CK $8 / 18$ is normally seen in embryonic cells and lost in adult squamous epithelium. CK8/18 play a role in tumor progression and metastatic potential as these are expressed in the poorly differentiated and not well differentiated squamous cell carcinomas.

The expression of CK 8/18 in SCC of oral cavity is an independent prognostic marker and indicates a decreased overall and progression free survival [5].

The present study was conducted to assess the incidence of oral cancer in eastern U.P. and to establish the correlation between expression of CK 8 and CK18 with tumor differentiation

\section{Material and Methods}

The present study has been conducted on the biopsy specimens received in department of pathology from inpatients and outpatients admitted in dental, surgery and ENT department during August 2014 to September 2015. A total of 104 paraffin embedded histological blocks were processed and sections were stained with Haematoxylin and Eosin ( $\mathrm{H} \& \mathrm{E})$ for morphological diagnosis after concordance of double blind evaluation by two independent pathologists.

Out of 104 cases, 60 (59.69\%) were invasive squamous cell carcinoma, 4 cases $(3.8 \%)$ were oral intraepithelial neoplasia III (OIN-III) and $40(38.46 \%)$ benign and inflammatory oral lesions served as a control. Cases with dissimilar diagnosis or unsatisfactory material were excluded from the study.

Immunohistochemical (IHC) staining was performed by Biogenex Super sensitive detection system (USA), using primary antibodies included Anticytokeratin 8 (AM142-5M, MU142-UC) and Anticytokeratin 18 (AM1B-5M, MU143-UC) from BIOGENEX company USA.

A positive control was used for every antibody to eliminate the possibility of wrong interpretation. Cytoplasmic staining was taken as positive in epithelium and number of cells showing positivity was graded as follow-

$<5 \%$ reactive cells $=$ Negative

$5 \%-30 \%$ reactive cells $=+($ Weak intensity $)$

$30 \%-60 \%$ reactive cells $=++($ Moderate intensity)

$>60 \%$ reactive cells $=+++($ Maximum intensity $)$

\section{Results}

Out of total 104 cases, 40 cases $(38.46 \%)$ were classified as benign and inflammatory lesions that served as control, 4 cases $(3.85 \%)$ as oral epithelial dysplasia grade III (OIN III) and 60 cases (57.69\%) were of invasive squamous cell carcinomas. The patient characteristics in the present study are as in Table $\mathbf{1}$.

On immunohistochemical analysis of CK8/18 expression, cytokeratin 8 positivity was observed in 34 out of 60 cases (56.67\%) of invasive squamous cell carcinomas with maximum intensity in $17 / 60(28.33 \%)$ cases and no expression 
was seen in control and oral intraepithelial lesions while cytokeratin 18 was expressed in 25 cases (41.67\%) out of 60 cases of invasive squamous cell carcinomas with maximum intensity seen in 5/60 (8.34\%) cases and its expression was also absent in all the benign cases as well as in oral intraepithelial lesions. (Figure 1,2,3).

In well differentiated squamous cell carcinoma, maximum intensity of CK 8 was seen in 8 out of 38 (21.05\%) cases whereas in poorly differentiated carcinomas, maximum intensity was seen in 3 out of $5(60 \%)$ cases. (Table 2)

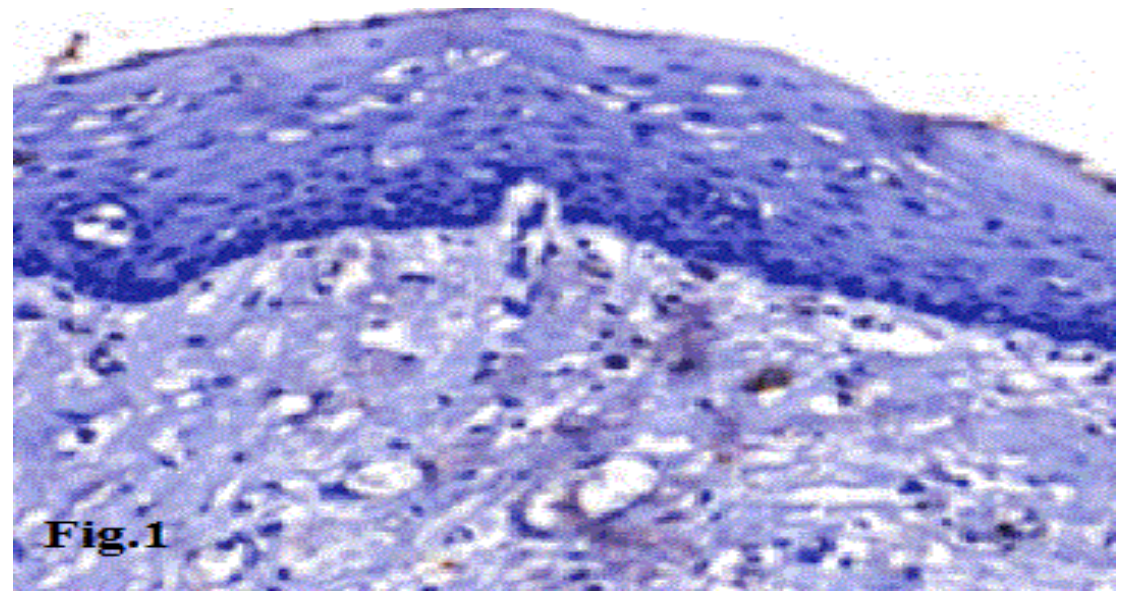

Figure-1: Photomicrograph showing Non expression of cytokeratin 8/18 seen in normal stratified squamous epithelium(X100)

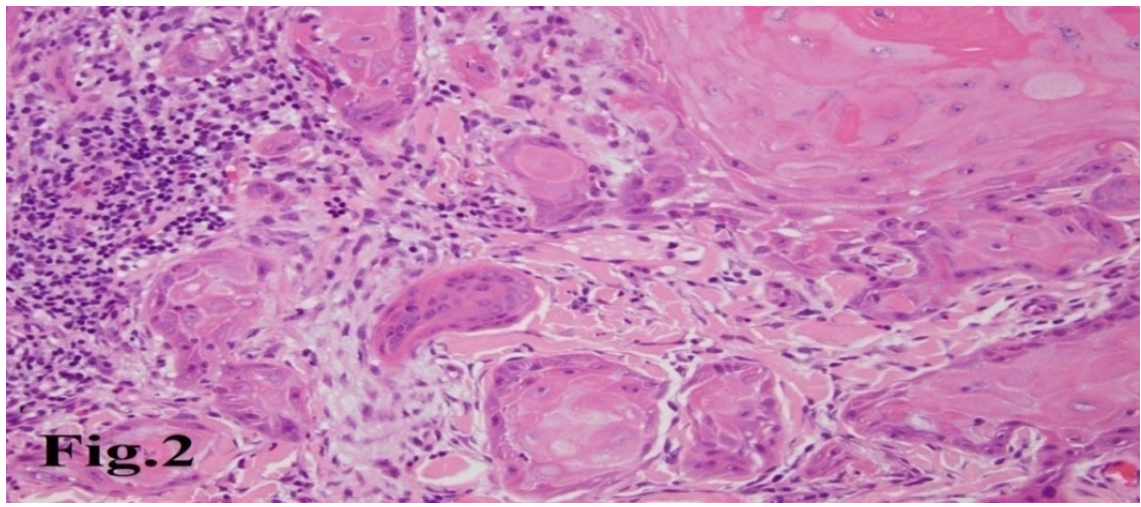

Figure-2:Photomicrograph showing nests of malignant tumour cells invading into the stroma(H\&E X400)

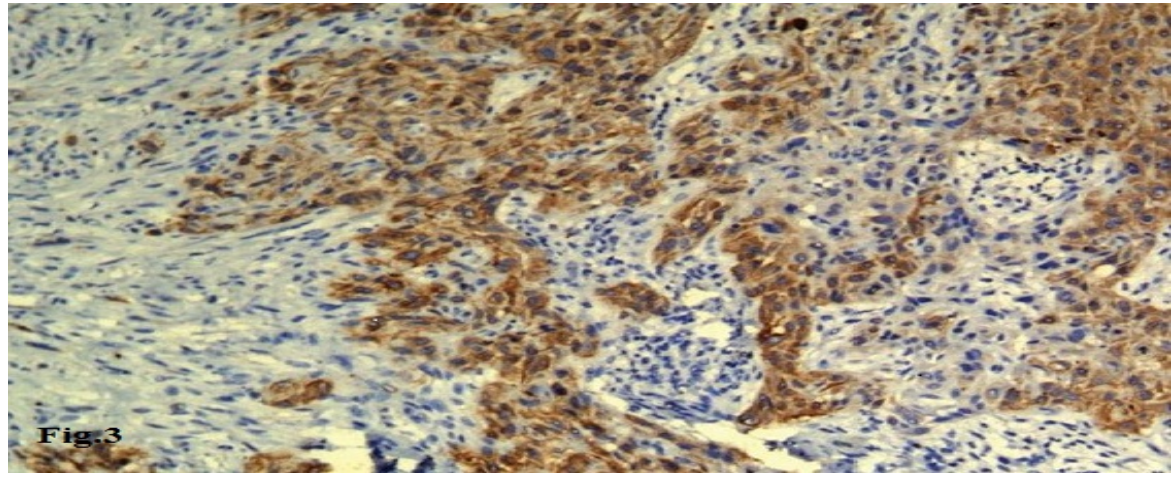

Figure-3: Photomicrograph showing cytokeratin 8/18 immunopositivity by invading tumour cells 
While reaction intensity of CK18 expression was maximum in $40 \%$ cases in poorly differentiated carcinomas as compared to $5.26 \%$ in well differentiated squamous cell carcinoma. All the results were statistically analysed using chi square test and the $\mathrm{p}$ value was found to be highly significant $(<0.001)$.

when control was compared with invasive oral carcinoma while it was not significant $(\mathrm{p}<0.05)$ when oral epithelial dysplasia grade 3 was compared with invasive oral carcinoma. (Table 3)

Table-1: Characteristics of 64 patients with oral squamous cell carcinoma and OIN III.

\begin{tabular}{|c|c|c|}
\hline Characteristics & Category & Cases \% \\
\hline \multirow[t]{2}{*}{ GENDER } & MALE & $53(82.81)$ \\
\hline & FEMALE & $11(17.19)$ \\
\hline \multirow[t]{2}{*}{ AGE } & $>50$ & $36(56.25)$ \\
\hline & $<50$ & $28(43.75)$ \\
\hline \multirow[t]{2}{*}{ TOBACCO(ANY FORM) } & YES & $58(90.6)$ \\
\hline & NO & $6(9.4)$ \\
\hline \multirow[t]{2}{*}{ GEOGRAPHIC DATA } & URBAN & $24(37.5)$ \\
\hline & RURAL & $40(62.5)$ \\
\hline \multirow{4}{*}{$\begin{array}{l}\text { HISTOLOGICAL } \\
\text { DIFFRENTIATION }\end{array}$} & OIN III & 4 \\
\hline & WELL & 38 \\
\hline & MODERATE & 17 \\
\hline & POOR & 5 \\
\hline \multirow[t]{2}{*}{ LYMPH NODE STATUS } & NOT INVOLVED & $45(70.13)$ \\
\hline & INVOLVED & $19(26.69)$ \\
\hline
\end{tabular}

Table-2: Distribution of cases according to intensity of immmunoexpression of CK 8 and CK 18

\begin{tabular}{|c|c|c|c|c|c|}
\hline IHC & & $\mathrm{NO}(-)$ & WEAK $(+) \%$ & MODERATE(++)\% & MAXIMAL(+++)\% \\
\hline \multirow[t]{3}{*}{ CK8 } & WELL & $20(52.64)$ & $6(15.78)$ & $4(10.53)$ & $8(21.05)$ \\
\hline & MODERATE & $5(29.41)$ & $2(11.64)$ & $4(23.54)$ & $6(35.29)$ \\
\hline & POOR & $1(20)$ & $0(0)$ & $1(20)$ & $3(60)$ \\
\hline \multirow[t]{3}{*}{ CK18 } & WELL & $24(63.16)$ & $8(21.05)$ & $4(10.53)$ & $2(5.26)$ \\
\hline & MODERATE & $10(58.82)$ & $3(17.65)$ & $1(5.88)$ & $3(17.65)$ \\
\hline & POOR & $1(20.0)$ & $1(20.0)$ & $1(20.0)$ & $2(40.0)$ \\
\hline
\end{tabular}


Research Article

Table-3: $\mathrm{Z}$ test for testing significance of difference between two proportions

\begin{tabular}{|l|c|c|c|c|}
\hline HISTOLOGY & \multicolumn{2}{|c|}{ CK8 } & \multicolumn{2}{c|}{ CK18 } \\
\hline OIN III VS INVASIVE ORAL & Z VALUE & P VALUE & Z VALUE & P VALUE \\
CARCINOMA & 2.1989 & P $<0.05$ & 1.6537 & P $>0.05($ not \\
CONTROL VS INVASIVE ORAL & 5.8603 & P $<0.001$ & 4.7140 & P $<0.001$ \\
CARCINOMA & & & & \\
\hline
\end{tabular}

\section{Discussion}

A total of 104 cases were studied which include histologically diagnosed cases of preinvasive and invasive lesions over various regions in oral cavity. In the present study, the data for gender cases $53(82.81 \%)$ males and 11 cases $(17.19 \%)$ females are in concordance with the study of Oliver et al [6]. Oral cancer was found to be more common among males.

This may be due to their addiction to tobacco chewing and smoking, which is most important risk factor for oral cancer. The male to female ratio in the present group of patients was 4.9:1. Durazzo et al [7] and Bhat et al [8] have also described male preponderance in oral cancer patients in western countries as well as India.

Cases from rural areas predominated over urban population. As such these findings could not be compared with the finding of others due to paucity of such work available in literature. In the present study peak incidence was seen in fourth and fifth decade of life. Similar findings were reported by Wahi et al [9] and Vasudevan et al[ 10] whereas Langdon et al [11] reported higher mean age( $63.6 \mathrm{yrs})$.

The reason for earlier occurrence of carcinoma among Indian people might be habit of tobacco chewing and smoking started early in life and prevailing poor socioeconomic conditions which affect the general nutritional status of the individual.
Tobacco addiction has been widely implicated in the etiology of oral cancers. In the present study, 58 $(90.62 \%)$ were tobacco users, which strongly suggest a close relationship between tobacco use and cancer of oral cavity. Jussawala et al [12] stressed similarly upon tobacco chewing and smoking as important risk factor for development of oral cancers.

No expression of CK8/18 was seen in control tissue. This was in accordance with Matthias C et al [13] who reported CK 8 was not detected in normal mucosa $(n=57)$ except for very mild and incidental expression in cells of stratum basale.

CK 8 expression was found in 34/60 (56.67\%) and CK 18 expression was found in $25 / 60(41.67 \%)$ of oral squamous cell carcinoma. Thomas $\mathrm{F}$ et al [5] also reported that detectable levels of CK8/18 (CK8/18>1\%) in $66.7 \%(120 / 180)$ cases of the oral squamous cell carcinoma and $13 \%(3 / 23)$ of the oral leukoplakia and dysplasia. Rao V et al [14] also reported that aberrant expression of CK1 in 30\%, CK8 in 54\%, CK18 in 44\% and vimentin in $85 \%$ of tumors.

CK8 expression was seen in $18 / 38(47.37 \%)$ cases of well, $12 / 17$ cases $(70.59 \%)$ of moderately and $4 / 5$ cases $(80 \%)$ of poorly differentiated oral squamous cell carcinoma while CK 18 expression was seen in 14/38 (3.84\%) of well, $7 / 17(41.18 \%)$ of moderately and $4 / 5$ 
Research Article

(80\%) Of poorly differentiated oral squamous cell carcinoma. Similarly in a study of 48 patients with biopsy proven squamous cell carcinoma of oral cavity who underwent surgery with neck dissection. RaoV et al [14] found expression of CK8, CK18 and vimentin in $57 \%$ cases of poorly differentiated, $36 \%$ of moderately and $7 \%$ of well differentiated tumors.

In our study, among 34 positive cases maximal intensity of CK8 immunoexpression was seen in most cases $(17 ; 48.57 \%)$ while $9(26.47 \%)$ cases have moderate and 8 cases $(22.85 \%)$ have mild intensity, while intensity of CK18 expression was mild in (12cases; 35.29\%), moderate intensity in 6 cases $(17.64 \%)$ and was maximal intensity in 7 cases $(20.58 \%)$. Similar findings are reported by Matthias C et al [13].

In our study significant $\mathrm{P}$ value was observed when oral epithelial dysplasia grade III was compared to invasive oral carcinoma similar to Thomas F et al [5] who found the expression of CK8/18 were significantly correlated in the chi square test with dysplastic transformation in leukoplakia $(\mathrm{P}<0.01)$ and were significantly higher expressed in OSCCs $(\mathrm{p}<0.01)$

During the course of this study it was found that in majority of the cases there was undue delay in the presentation due to earlier ignorance of the patient and lack of awareness (degree of suspicion) of the possibility of malignancy on the part of medical attendant while examining the patient. In the present study tumor cells expressed CK8 to strong levels while no expression was seen in normal tissue and OIN III. Hence CK8 can be used as a supportive marker for diagnosis of oral squamous cell carcinoma.

Aberrant expression of CK8/18 could be correlated with differentiation and recurrence and showed a great promise to be used as prognostic marker for human oral cancer. CK8/18 positive carcinoma revealed a significantly decreased prognosis. Further studies with larger sample size will help in establishing these markers in prognostication of oral cancer and underlying mechanism of the role of CK8/18 in malignant transformation might allow development of therapeutic targets in near future.

Funding: Nil, Conflict of interest: None initiated, Permission from IRB: Yes

\section{References}

1. Kale AD, Mane DR, Babji D, Gupta K. Establishment of field change by expression of cytokeratins 8/18, 19, and MMP-9 in an apparently normal oral mucosa adjacent to squamous cell carcinoma: A immunohistochemical study. J Oral Maxillofac Pathol. 2012 Jan;16(1):10-5. doi: 10. 4103/0973-029X.92966.

2. Petersen PE. The World Oral Health Report 2003: continuous improvement of oral health in the $21 \mathrm{st}$ century--the approach of the WHO Global Oral Health Programme. Community Dent Oral Epidemiol. 2003 Dec;31 Suppl 1:3-23.

3. Bhargava A, Saigal S, Chalishazar M. Histopathological Grading Systems in Oral squamous cell carcinoma: A Review. Jour Int Oral Health 2010. vol2 (4):1-10.

4. Bahadur S, Amatya RC, Iyer S, Kumar KL, Chattopadhya TK. Study of distribution of cervical lymph node metastasis from squamous cell carcinoma of head and neck. Indian J Cancer. 1983 Jul-Aug;20 (3):142-6.

5. Fillies $\mathrm{T}$, Werkmeister R, Packeisen $\mathrm{J}$, Brandt $\mathrm{B}$, Morin P, Weingart D, Joos U, Buerger H. Cytokeratin $8 / 18$ expression indicates a poor prognosis in squamous cell carcinomas of the oral cavity. BMC Cancer. 2006 Jan 13;6:10.

6. Durazzo MD, Araujo CEN, Neto JSB, Potenza AS, Costa Pedro, Takeda $F$ et al. clinical and epidemiological features of oral cancer ina medical school teaching hospital from 1994 to 2002: increasing incidence in women, predominance of advanced local 
disease, and low incidence of neck metastases.CLINICS 2005; 60(4)293-298

7. Bhat SP, Ramesh NCN, Swetadri GK, D'souza H, Jayaprakash CS, Bhat V. Clinicopathological spectrum of malignancies of oral cavity and oropharynx - our experience in a referral hospital. World articles in Ear, Nose and Throat 2010; 3(2)1-7.

8. Wahi PN. The epidemiology of oral anc oropharyngeal cancer. A report of the study in Mainpuri district, Uttar Pradesh, India. Bull World Health Organ. 1968; 38(4):495-521.

9. Padmanabhan TK, Vasudevan DM. A statistical analysis of cancer registered at the Regional Cancer Centre, Trivandrum. Indian J Cancer. 1982 Sep-Oct; 19(4):189-96.
10. Langdon JD, Harvey PW, Rapidis AD, Patel MF, Johnson NW, Hopps R. Oral cancer: the behaviour and response to treatment of 194 cases. J Maxillofac Surg. 1977 Nov; 5(4):221-37.

11. Jussawalla DJ, Deshpande VA. Evaluation of cancer risk in tobacco chewers and smokers: an epidemiologic assessment. Cancer. 1971 Jul;28(1):244-52.

12. Matthias C, Mack B, Berghaus A, Gires O. Keratin 8 expression in head and neck epithelia. BMC Cancer. 2008 Sep 22;8:267. doi: 10.1186/1471-2407-8-267.

13. Rao V, Chukar D,Vaidya M, Sawant S, Dcruz A, Kane S.Role of cytokeratin 8 and vimentin as prognostic markers in oral cancers. Jour Clin Oncol 2008; 26(15S):17-30.

\section{How to cite this article?}

Mitra S.K, Mishra R.K, Rai R, Rai P, Arya M.L. Study of expression patterns of cytokeratin 8 and 18 in oral cancers. Trop J Path Micro 2016;2(3):82-88.doi: 10.17511/jopm.2016.i03.01 